\title{
Bir Konutun Dış Duvarları İçin Isıtma ve Soğutma Yüklerine Göre Optimum Yalıtım Kalınlığın Tespiti ve Enerji Tasarrufu Analizi
}

\author{
Aynur Uçar ${ }^{1 *}$, Muhammed Usame Dumrul ${ }^{1}$ \\ ${ }^{1}$ Fırat Üniversitesi, Mühendislik Fakültesi, Makina Müh. Bölümü, Elazığ, Türkiye (ORCID: 0000-0001-5973-3741)
}

(İlk Geliş Tarihi 3 Temmuz 2019 ve Kabul Tarihi 24 Temmuz 2019)

(DOI: 10.31590/ejosat.586176)

ATIF/REFERENCE: Uçar, A. \& Dumrul, M. U. (2019). Bir Konutun Dış Duvarları İçin Isıttma ve Soğutma Yüklerine Göre Optimum Yalıtım Kalınlığın Tespiti ve Enerji Tasarrufu Analizi. Avrupa Bilim ve Teknoloji Dergisi, (16), 740-749.

$\ddot{\mathbf{O z}}$

Artan nüfus, gelişen teknoloji enerjiye olan talebi sürekli olarak artırmaktadır. Bu durum Türkiye gibi gelişmekte olan ülkeleri zorunlu enerji tasarrufuna yöneltmiştir. Yapılarda enerji tasarrufu için kullanılan en etkin yöntemlerden biri 1sı yalıtımıdır. Bu çalışmada iki farklı duvar modeli (dıştan yalıtımlı duvar ve sandviç duvar), üç farklı yakıt çeşidi (doğalgaz, kömür ve elektrik) ve iki farklı yalıtım malzemesi sıkıştırılmış polistiren (XPS) ve genleştirilmiş polistiren (EPS) kullanılarak yalnız ısıtma, yalnız soğutma ve hem ısıtma hem de soğutma durumunda Malatya ili için optimum yalıtım kalınlığı, toplam maliyet, enerji tasarrufu ve geri ödeme süresi hesaplanmıştır. Elde edilen sonuçlardan, hem isıtma ve hem de soğutma durumu için optimum yalıtım kalınlıkları $0.0549 \mathrm{~m}$ ile $0.0836 \mathrm{~m}$ arasında, enerji tasarrufları $24.79 \mathrm{TL} / \mathrm{m}^{2}$ ile $60.45 \mathrm{TL} / \mathrm{m}^{2}$ arasında ve geri ödeme sürelerinin ise 2.5714 ve 4.2062 yll arasında değiştiği gözlemlenmiştir.

Anahtar Kelimeler: Optimum yalıtım kalınlığı, Enerji tasarrufu, Isıtma ve soğutma maliyeti.

\section{Determination of optimum insulation thickness and energy saving analysis according to heating and cooling loads for exterior walls of a house in Malatya}

\begin{abstract}
Growing population and developing technology continuously increases the demand for energy. One of the most effective methods for energy saving in buildings is thermal insulation. In this study, the optimum insulation thickness, total cost, energy saving and reimbursement period for Malatya city were calculated for two different wall structures (externally insulated walls and sandwich walls), three different types of fuel (natural gas, coal and electricity) and two different insulation materials (extruded polystyrene (XPS), expanded polystyrene (EPS)) for only heating, only cooling and both heating and cooling conditions. According to the results, the optimum insulation thicknesses is between $0.0549 \mathrm{~m}$ and $0.0836 \mathrm{~m}$, the energy savings is between $24.79 \mathrm{TL} / \mathrm{m}^{2}$ and $60.45 \mathrm{TL} / \mathrm{m}^{2}$ and payback period is between 2.5714 and 4.2062 years for both heating and cooling conditions.
\end{abstract}

Keywords: Optimum insulation thickness, Heating and cooling cost, Energy savings.

\footnotetext{
*Sorumlu Yazar: Frrat Üniversitesi, Mühendislik Fakültesi, Makina Bölümü, Elazı̆̆, Türkiye, ORCID: 0000-0001-5973-3741, aucar@firat.edu.tr
} 


\section{Giriş}

Ülkelerin en önemli sorunlarından biri enerjinin tüketilmesidir. Enerji tüketiminin başlıca sorunu çevre kirliliğidir. sanayi ve bina sektörü, en fazla enerji tüketimine sahip olan sektörlerdir. Binalardaki enerji tüketimini azaltmak için kış aylarında ısı kayıplarını, yaz aylarında da ısı kazançlarını azaltmak gerekmektedir. Bunun için en etkin yol bina elemanlarının yalıtılmasıdır. Ülkemiz, yenilenebilir enerji kaynakları açısından zengin olmasına karşılık, enerji ihtiyacının önemli bir kısmını dışarıdan ithal etmektedir (Ogulata 2002, Kaygusuz 2004). Binalara uygulanan 1sı yalıtım malzemesinin kalınlığı arttıkça, 1sı kazanç ve kayıplarını düşecek, ancak yalıtım maliyeti artacaktır. Bu nedenle yalıtım kalınlığı seçilirken en uygun yalıtım kalınlığı belirlenmelidir. Optimum yalıtım kalınlığı, maliyet analizi yapılarak belirlenmelidir. Çomaklı ve Yüksel (2003) Türkiye'deki soğuk iklim bölgesinden seçilen üç şehir (Erzurum, Kars ve Erzincan) için yalıtım optimum kalınlığını, derece gün metodu kullanarak bulmuşlardır. Bolattürk (2003) binanın duvar ve çatısında kullanılan yalıtım malzemesinin optimum kalınlıklarını ve enerji tasarruflarını Derece-Gün metodu kullanarak, Isparta ili için tespit etmişlerdir. Kürekçi (2016), Türkiye'nin 81 ili için optimum yalıtım kalınlığını dört farklı yakıt türü (doğal gaz, kömür, akaryakıt ve sıvılaştırılmış petrol gazı) ve 5 farklı yalıtım malzemesi (ekstrüde polistiren, genleşmiş polistiren, cam yünü, taş yünü ve poliüretan) incelemişlerdir. Nematchoua vd. (2017), Kamerun'da iki farklı iklim bölgesinden seçtiği iki şehir için optimum yalıtım kalınlığını, enerji tasarrufunu ve geri ödeme süresini bulmuşlardır. Bunun için, yalıtım malzemesinin maliyeti ve enerji tüketiminin bugünkü değeri ve binanın 22 yıllık kullanım ömrü boyunca toplam maliyetini içeren ekonomik bir model kullanmışlardır. Çalışmalarında, yalıtım malzemesi olarak ekstrüde polistiren ve iki farklı duvar yapısını (beton blok ve sıkıştırılmış stabilize toprak blok duvar) seçmişlerdir. Evin ve Uçar (2019), bir binanın dış duvar, kolon, taban ve çatısına uygulanan yalıtım malzemesinin optimum kalınlığı, Türkiye'nin dört farklı iklim bölgesinden seçilen 4 il ve 4 farklı yalıtım malzemesi için hesaplamışlardır. Hesapladıkları bu yalıtım kalınlığı için ısıtma ve soğutma yükü ve maliyetlerini bulmuşlardır.

Aktemur (2017) Türkiye'nin dört farklı iklim bölgelerinden seçilen dört şehir için optimum yalıtım kalınlığı, 15 yıl boyunca enerji tasarrufu ve geri ödeme süreleri altı farklı yakıt (motorin, doğal gaz, LPG, elektrik, kömür ve akaryakıt ) ve yalıtım malzemeleri (ekstrüde polistiren, genleşmiş polistiren, cam yünü, taş yünü, polyizosiyanurat ve poliüretan için hesaplamışlardır. Kaynaklı (2008), yoğuşmayı dikkete alarak farklı yalıtım uygulamaları için, binaların dış duvarlarında kullanılan ısı yalıtım malzemesinin optimum kalınlığını bulmuşlardır. Dombayci vd. (2017) Türkiye'de dört farklı iklim bölgesinde seçilen iller için bina dış duvarının optimum yalıtım kalınlığını, yaşam döngüsü maliyet analizi olarak da adlandırılan enflasyon ve faiz oranının etkisinin dikkate alındığı termoekonomik yöntemi kullanarak hesaplanmıştır $\mathrm{Bu}$ çalışmada yalıtım malzemesi olarak, polistiren ve poliüretan kullanılmıştır. Canbolat ve arkadaşları (2018), bina duvarları için 1sı yalıtım kalınlıklarını soğutma ve 1sıtma enerjisi ihtiyaçlarına göre hesaplamışlardır. Bu amaçla, ömür maliyet analizini (life cycle cost) kullanmışlardır. İstanbul için optimum yalıtım kalınlığını 4.7 cm olarak bulmuşlardır. Işsk ve Tuğan (2017) Tunceli, Hakkâri ve Kars illeri için derece-gün yöntemi kullanılarak dış duvarlara uygulanacak optimum yalıtım kalınlığ olarak bulmuşlardır. Özel (2018),Kars ilindeki bina dış duvarlarının optimum yalıtım kalınlığını meteorolojik verileri kullanılarak ısıtma yükleri derece-gün olarak güneş ışınımı değerleri dikkate alınarak ve alınmadan hesaplmıştır. Demir (2018), soğutma sistemleri için belirli bir yalıtım malzemesi hacmi veya iç hacim için ısı yalıtım malzemesinin optimum dağılımının genel bir çözümü önermiş ve ayrıca bir örnek çalışma ile açıklamıştır

Bu çalışmada, iki farklı yalıtım malzemesi ve iki farklı yakıt türü için Malatya illi için yalıtım malzemesinin optimum kalınlıkları, enerji tasarrufları ve geri ödeme süreleri sadece 1sıtma, sadece soğutma ve hem ısıtma hem de soğutma için ayrı ayrı hesaplanmıştır.

\section{- Materyal ve Metot}

\subsection{Bina Duvarlarının Yapısı}

Bir binada en çok ısı kaybeden yerler bina duvarlarıdır. Bu nedenle, bina dış duvarlarının ısı yalıtımı, binadan olan ısı kaybı hesabında önemli bir faktördür. Binalardaki ısı kayıpları ve kazançlar en fazla dış duvarlardan, pencerelerden, çatıdan, yerlerden ve hava sızmasından kaynaklanır. Bu çalışmada, ısı kayıplarından ve sadece dış duvarlardan meydana gelen kazanımlar dikkate alınarak teorik maksimum yalıtım kalınlı̆̆ı hesaplanmıştır.

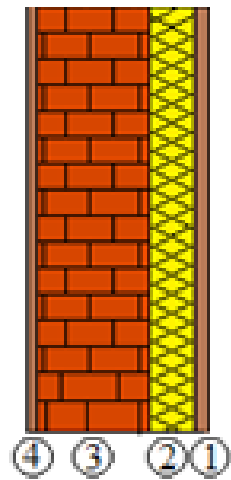

(a)

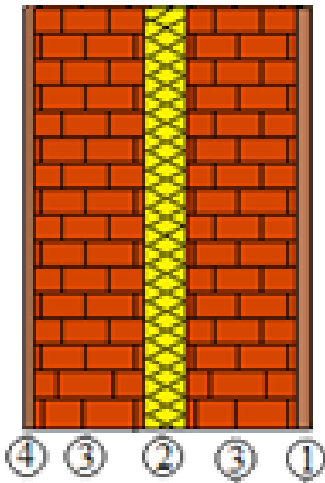

(b) 
Bu çalışmada, iki farklı duvar tipi çalışılmıştır. Bunlardan biri dıştan yalıtımlı duvar olup, $3 \mathrm{~cm}$ dış sıvadan (1), yalıtım malzemesi (2), $15 \mathrm{~cm}$ yatay delikli tuğla (3) ve $2 \mathrm{~cm}$ iç sıva (4) oluşmaktadır. Sandviç duvar ise $3 \mathrm{~cm}$ dış sıva (1), arasında yalıtım malzemesi (2) ve 2 parçadan biri $13.5 \mathrm{~cm}$ (3) ve $8 \mathrm{~cm}$ yatay delikli tuğla (3) ve $2 \mathrm{~cm}$ iç sıvadan (4) oluşmaktadır (Şekil 1). Bu çalışmada XPS (Ekstrüde polistren) ve EPS (genleştirilmiş polistren) yalıtım malzemesi olarak seçilmiştir. Malzeme seçiminde, bu malzemelerin illerde bulunabilme ve uygulanma kolaylığı özellikle etkili olmuştur. Malzemelere ait fiziksel özellikler Tablo 1'de verilmiştir. Bu çalışmada, 1 sıtma için $18^{\circ} \mathrm{C}$, soğutma için $22^{\circ} \mathrm{C}$ denge sıcaklıklarını için derece gün değerleri seçilmiştir. Çalışmada kullanılan yakıtların alt 1sıl değerleri, 1sıl verim ve fiyatları Tablo 2'de görülmektedir. Malatya ili Türkiye'nin 3. derece gün bölgesindedir. Malatya ilinin 15 oC denge sıcaklığg için 1 sitma derece-gün değeri $2461{ }^{\circ} \mathrm{C}$.gün, soğutma derece-gün değeri ise $407^{\prime}$ dir.

Tablo 1. Diș duvar malzemelerinin fiziksel özellikleri

\begin{tabular}{l|ccc|ccc}
\hline \multirow{2}{*}{} & \multicolumn{3}{|c|}{ Diştan Yalıtımlı Duvar } & \multicolumn{3}{c}{ Sandviç Duvar } \\
\cline { 2 - 7 } & $\begin{array}{c}\text { Kalınlık } \\
(\mathrm{m})\end{array}$ & $\begin{array}{c}\mathrm{k} \\
(\mathrm{W} / \mathrm{mK})\end{array}$ & $\begin{array}{c}\mathrm{R} \\
\left(\mathrm{m}^{2} \mathrm{~K} / \mathrm{W}\right)\end{array}$ & $\begin{array}{c}\text { Kalınlık } \\
(\mathrm{m})\end{array}$ & $\begin{array}{c}\mathrm{k} \\
(\mathrm{W} / \mathrm{mK})\end{array}$ & $\begin{array}{c}\mathrm{R} \\
\left(\mathrm{m}^{2} \mathrm{~K} / \mathrm{W}\right)\end{array}$ \\
\hline İç sıva(kireç esasl1) & 0.02 & 0.87 & 0.2298 & 0.02 & 0.87 & 0.2298 \\
Yatay delikli tuğla & 0.13 & 0.45 & 0.2888 & 0.135 & 0.45 & 0.2888 \\
Yatay delikli tuğla & & & & 0.08 & 0.45 & 0.1777 \\
Diş sıva(çimento esasli) & 0.02 & 1.4 & 0.0143 & 0.03 & 0.87 & 0.0345 \\
$\mathrm{R}_{\mathrm{i}}$ & & & 0.1667 & & & 0.1667 \\
$\mathrm{R}_{\mathrm{o}}$ & & & 0.0454 & & & 0.0454 \\
$\mathrm{R}_{\text {duv }}$ (Yalıtım malzemesi hariç) & & & 0.5383 & & & 0.7474 \\
\hline
\end{tabular}

Tablo 2. Yakıt malzemesi parametreleri (Enerji dünyası dergisi, 2018)

\begin{tabular}{l|l|l|l}
\hline Yakıt & Alt 1sıl değer(Hu) & Verim $(\mathrm{n})$ & Yakıt fiyatı(C $\left.\mathrm{C}_{\text {yakıt }}\right)$ \\
\hline Doğalgaz & $34526000 \mathrm{~J} / \mathrm{m}^{3}$ & 0.93 & $1.06 \mathrm{TL} / \mathrm{m}^{3}$ \\
Kömür & $19794000 \mathrm{~J} / \mathrm{kg}$ & 0.65 & $0.68 \mathrm{TL} / \mathrm{kg}$ \\
Elektrik (soğutma için) & $3599000 \mathrm{~J} / \mathrm{kWh}$ & 0.99 & $0.47 \mathrm{TL} / \mathrm{kWh}$ \\
\hline
\end{tabular}

\subsection{Dış Duvarlar İçin Isıtma ve Soğutma Yükü}

Dış duvarların birim yüzeyinde meydana gelen 1sı kaybı,

$$
q=U \Delta T
$$

ile hesaplanır. Burada, U toplam 1sı transfer katsayısıdır ve yalıtımlı bir dış duvar için aşağıdaki gibi hesaplanır:

$$
U=\frac{1}{R_{i}+R_{\text {duvar }+R_{y a l}+R_{O}}}
$$

Burada, $\mathrm{R}_{\mathrm{i}}$ iç $1 \mathrm{~S} 1$ transfer direnci, $\mathrm{R}_{\mathrm{o}}$ dış $1 \mathrm{~S}$ transfer direnci olup, duvarın iç ve dış yüzeyindeki ısı transfer katsayıları sırasıyla 6 ve 22 $\mathrm{W} / \mathrm{m}^{2} \mathrm{~K}$ alınmıştır. $\mathrm{R}_{\mathrm{yal}}$ ise yalıtım malzemesinin 1 sıl direncidir ve

$$
R_{\text {yal }}=\frac{x}{k}
$$

olarak hesaplanır. Yalıtımsız duvar katmanlarının toplam direnci $\mathrm{R}_{\text {duvar,t }}$ olup, aşağıdaki denklem ile bulunur :

$R_{\text {duvar }, t}=R_{i}+R_{\text {duvar }}+R_{o}$

Toplam 1sı transfer katsayısı;

$$
U=\frac{1}{R_{w, t+R_{y a l}}}
$$

şeklinde hesaplanır. Duvarın birim yüzeyinde meydana gelen yıllık 1sı kayıbı,

$$
\begin{aligned}
& q_{y \iota l, H}=86400 H D D U \\
& q_{y \iota l, C}=86400 C D D U
\end{aligned}
$$

eşitliği yardımıyla hesaplanabilir. Birim alanı ısıtmak için gerekli olan yıllık enerji ihtiyacı (Evin ve Uçar, 2019),

$$
E_{y l l, H}=\frac{86400 \times \mathrm{HDD}}{\left(R_{y a l}+R_{w, t}\right) \times \eta}
$$

eşitliği ile hesaplanabilir. Soğutma için yıllık enerji ihtiyac1: 
$E_{y l l, C}=\frac{86400 \times \mathrm{CDD}}{\left(R_{y a l}+R_{w, t}\right) \times \mathrm{COP}}$

ile hesaplanır. Bu çalışmada COP, 2.5 alınmıştır.

\subsection{Optimum Yalıtım Kalınlığının ve Enerji Maliyetinin Hesabı}

Binaların dış duvarlarına uygulanacak yalıtım bina yüzeyindeki ısı kaybını önemli ölçüde azaltmaktadır. Optimum yalıtım kalınlığını belirlemek için maliyet analizinin yapılması gereklidir. Isıtma ve soğutma için yıllık enerji maliyeti aşağıdaki denklemlerle bulunur (Kurekci, 2016).

$$
\begin{aligned}
C_{A, H} & =\frac{86400 \times \mathrm{HDD} \times C_{\text {yaklt }}}{\left(R_{y a l}+R_{w, t}\right) \times \mathrm{Hu} \times \eta} \\
C_{A, C} & =\frac{86400 \times \mathrm{HDD} \times C_{e}}{\left.\left(R_{y a l}+R_{w, t}\right)\right) \times \mathrm{COP}}
\end{aligned}
$$

(11)Şimdiki değer faktörü

$$
\begin{gathered}
r=\frac{\mathrm{i}-\mathrm{g}}{1+\mathrm{g}} \\
\mathrm{PWF}=\frac{(1+\mathrm{r})^{\mathrm{N}}-1}{\mathrm{r} \times(1+\mathrm{r})^{\mathrm{N}}}
\end{gathered}
$$

şeklinde hesaplanır.

Tablo 5. Hesaplamalarda kullanılan parametreler (Evin ve Uçar, 2019; TÜİK,2018)

\begin{tabular}{ll}
\hline Parametre & Değeri \\
\hline Faiz oranı(i) & $\% 24$ \\
Enflasyon oranı(g) & $\% 21$ \\
Ömür süresi(N) & $10 \mathrm{yll}$ \\
Şimdiki değer faktörü(PWF) & 5.2910 \\
Yalıtım malzemesi & \\
EPS & \\
k $(\mathrm{W} / \mathrm{mK})$ & 0.039 \\
$\mathrm{C}_{\mathrm{y}}\left(\mathrm{TL} / \mathrm{m}^{3}\right)$ & 190 \\
$\mathrm{XPS}$ & \\
$\mathrm{k}(\mathrm{W} / \mathrm{mK})$ & 0.031 \\
$\mathrm{C}_{\mathrm{y}}\left(\mathrm{TL} / \mathrm{m}^{3}\right)$ & 240 \\
$\mathrm{HDD}\left({ }^{\circ} \mathrm{C}-\right.$ gün$)$ & \\
Malatya & 2461 \\
$\mathrm{CDD}\left({ }^{\circ} \mathrm{C}-\right.$ gün $)$ & \\
$\quad$ Malatya & 407 \\
\hline
\end{tabular}

Yalıtılmış binanın toplam ısıtma ve soğutma maliyeti:

$$
\begin{aligned}
& C_{t, H}=C_{A, H} P W F+C_{y} x \\
& C_{t, C}=C_{A, C} P W F+C_{y} x
\end{aligned}
$$

şeklinde hesaplanır. Yalıtılmış bir binanın hem ısıtma hem soğutma maliyeti ise (Kurekci, 2016):

$$
C_{t, H, C}=C_{A, H} P W F+C_{A, C} P W F+C_{y} x
$$

olarak hesaplanmaktadır.

Burada, $\mathrm{C}_{\text {yal }}$ yalıtım malzemesinin maliyeti olup, aşağıdaki gibi hesaplanır.

$$
C_{y a l}=C_{y} x
$$

Isıtma ve soğutma için elde edilecek enerji tasarrufu,

$$
\begin{aligned}
S_{A, H} & =\frac{86400 \times \mathrm{HDD} \times C_{\text {yaktt }}}{\left(R_{y a l}+R_{w, t}\right) \times \mathrm{Hu} \times \eta} P W-C_{y} x \\
S_{A, C} & =\frac{86400 \times \mathrm{HDD} \times C_{e}}{\left.\left(R_{y a l}+R_{w, t}\right)\right) \times \mathrm{COP}} P W F-C_{y} x
\end{aligned}
$$

Isıtma maliyeti minimum yapan optimum yalıtım kalınlığı aşağıdaki gibi hesaplanmaktadır. 


$$
x_{o p t, H}=\left(\frac{86400 \mathrm{HDD} C_{y a k t t} \mathrm{PWF} \mathrm{k}}{\mathrm{Hu} C_{y} \eta}\right)^{1 / 2}-R_{\text {duvar }, \mathrm{k}} \mathrm{k}
$$

Soğutma için optimum yalıtım kalınlığı ise:

$x_{\text {opt }, C}=\left(\frac{0.024 \mathrm{CDD} C_{e} \mathrm{PWF} \mathrm{k}}{C_{y} \mathrm{COP}}\right)^{1 / 2}-R_{\text {duvar }, t} k$

hesaplanır. Hem 1sıtma hem de soğutma için yalıtım malzemesinin optimum kalınlığı;

$x_{\text {opt }, H, C}=293.94\left(\frac{86400 \times \mathrm{HDD} \times C_{\text {yaklt }} \times \mathrm{PWF} \times \mathrm{k}}{\mathrm{Hu} \times \mathrm{Cy} \times \eta}+\frac{0.024 \times \mathrm{CDD} \times C_{e} \times \mathrm{PWF} \times \mathrm{k}}{\mathrm{Cy} \times \mathrm{COP}}\right)^{1 / 2}-R_{\text {duvar }, t} k$

ile hesaplanır.

Geri ödeme süresi ise;

$A=\frac{\text { Yalıtım maliyeti }}{\text { (Yalıtımsız binanın ısıtma maliyeti-Yalıtımlı binanın ısıtma maliyeti) }}$

ile hesaplanmaktadir.

\section{Araştırma Sonuçları ve Tartışma}

Toplam maliyeti etkileyen yalıtılmış bir binada iki önemli parametre mevcuttur. Bunlardan biri yalıtım maliyeti diğeri ise yakıt maliyetidir. Bilindiği gibi binalarda yalıtım kalınlığının artması 1sı kaybını düşürür. Böylelikle birim alanı 1sıtmak için gerekli olan enerji azalmakta toplam maliyet ise düşmektedir. Fakat yalıtım kalınlığı gerektiğinden daha fazla arttırmak, yalıtım maliyetini arttırır. Bununla birlikte yalıtım maliyetinin artması sonucu, belli bir kalınlıktan sonra toplam maliyet de artacaktır. Bu çalışmada Malatya ili için yalıtım malzemesinin optimum kalınlıkları, enerji tasarruf miktarı ve geri ödeme süreleri bulunmuştur.
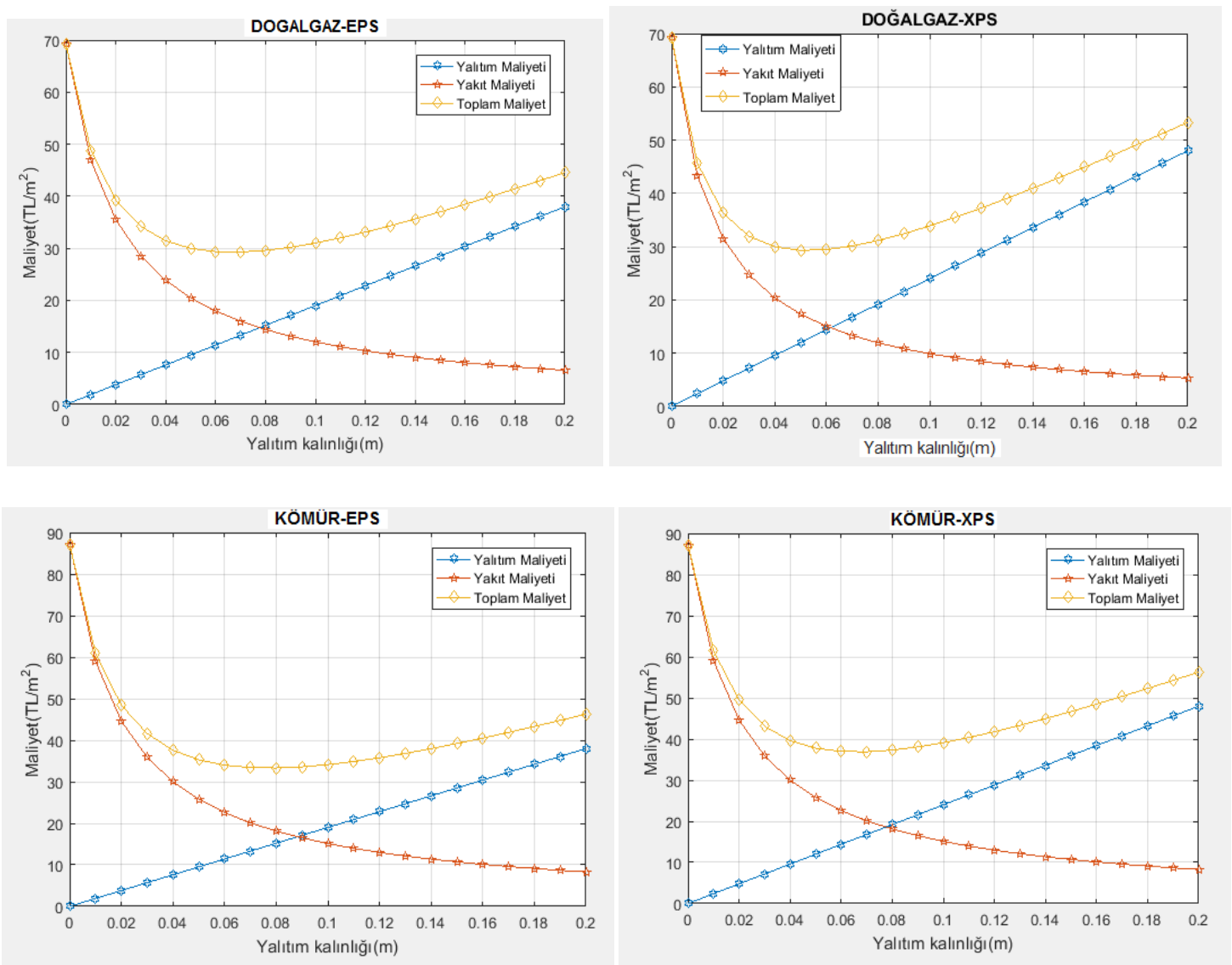

Şekil 2. Malatya ili için dıştan yalıtımlı duvar için iki farklı yalıtım malzemesi ve yakıt türü için maliyetin yalıtım kalınlığı ile değişimi

Şekil 2 ve Şekil 3'de dıştan yalıtımlı ve sandviç duvarlarda iki farklı yakıt türü ve yalıtım malzemesi için maliyetin yalıtım kalınlı̆̆g ile değişimi görülmektedir. Konutun dış duvarındaki yalıtım malzemesinin kalınlığı arttırıldığında, toplam ısıl direncinde atması sonucu 
duvardan olan 1sı kayıp miktarı azalmaktadır. Isı kayıp miktarının azalmasıla yakıt maliyeti azalmaktadır. Ayrıca yalıtım kalınlığı arttıkça yalıtım maliyet de artmaktadır. Çünkü uygulanan yalıtım kalınlığı arttıkça daha fazla yalıtım malzemesi gerekmektedir. Yalıtım maliyetinin artmasından dolayı, toplam maliyette artmaktadır. Toplam maliyetinin minimum olduğu yalıtım malzemesinin kalınlığı, optimum kalınlıktır. Sandviç duvar ve dıştan yalıtımlı duvar için bakıldığında yalıtım kalınlığının artmasıyla toplam maliyet, sandviç duvarda daha fazla olmaktadır. Duvar için seçilmiş yapı bileşenlerin 1 sı iletim katsayıları ile duvar bileşenlerin farklılığından dolayı, sandviç duvar ile dıştan yalıtımlı duvarın optimum yalıtım kalınlıkları da farklı olmaktadır.
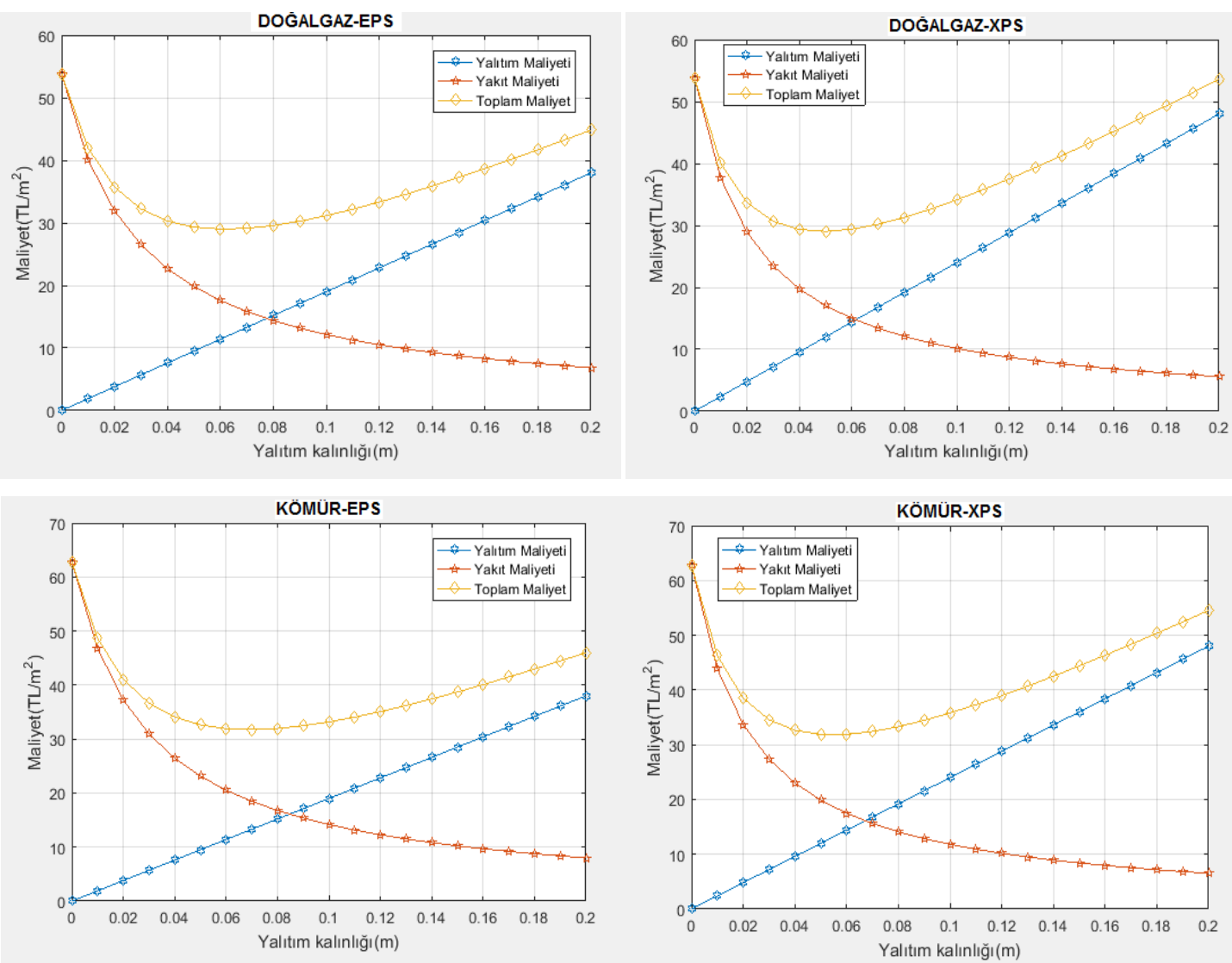

Şekil 3. Malatya ili için sandviç yalıtımlı duvar için iki farklı yalıtım malzemesi ve yakıt türü için maliyetin yalıtım kalınlığı ile değişimi
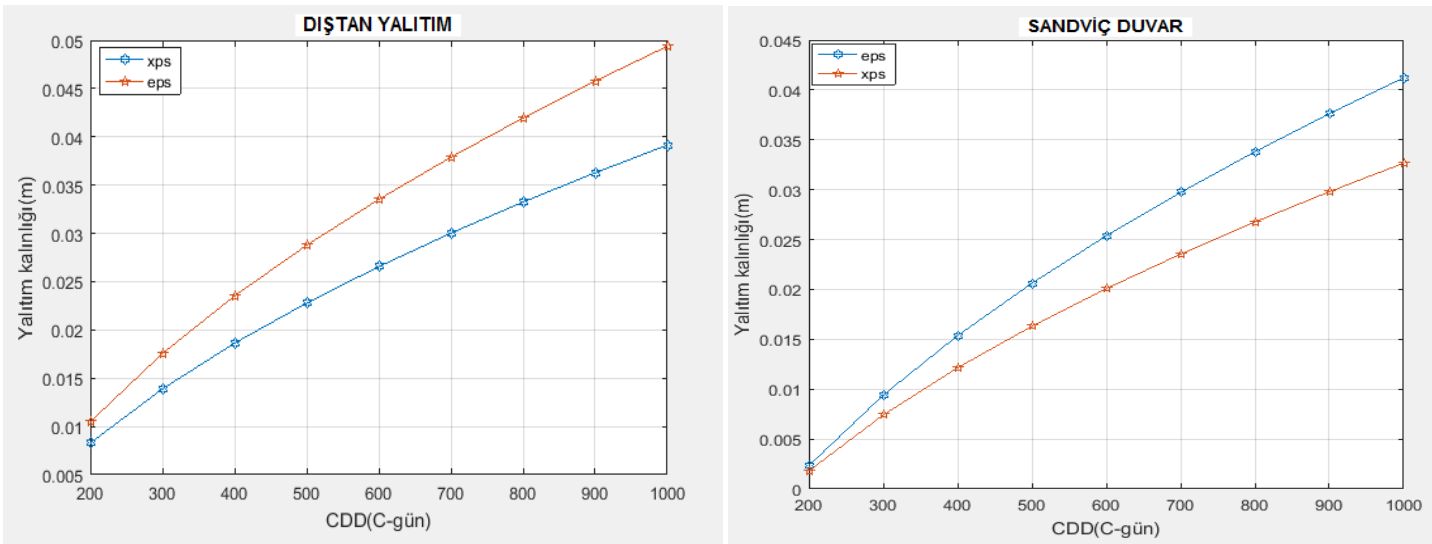

Şekil 4. Optimum yalıtım kalınlığının iki farklı duvar türü ve yalıtım malzemesi için soğutma derece gün sayısı ile değişimi

Şekil 4'de optimum yalıtım kalınlığının iki farklı duvar türü ve yalıtım malzemesi için soğutma derece gün sayısı ile değişimi doğal gaz yakıt türü için verilmiştir. Şekil 5'de ise optimum yalıtım kalınlığının iki farklı duvar türü, yalıtım malzemesi ve yakıt türü için ısıtma derece gün sayısı ile değişimi verilmektedir. Grafiklerden görüldüğü gibi, ssıtma derece-gün değeri büyük olan yani daha soğuk iklim bölgelerinde bulunan illerde optimum yalıtım kalınlığı daha fazla olmaktadır. Yalıtım malzemesi olarak kullanılan EPS ve XPS için incelendiğinde 1 sı iletim katsayısı büyük olan EPS ile yalıtım malzemesinin kalınlı̆̆ı daha büyük olmaktadır. Derece gün sayısının düşük olduğu sıcak iklim bölgelerinde yalıtım kalınlıkları daha küçük olmaktadır. Aynı durum soğutma derece-gün sayısı ile yalıtım kalınlığının değişimi için de geçerlidir. 

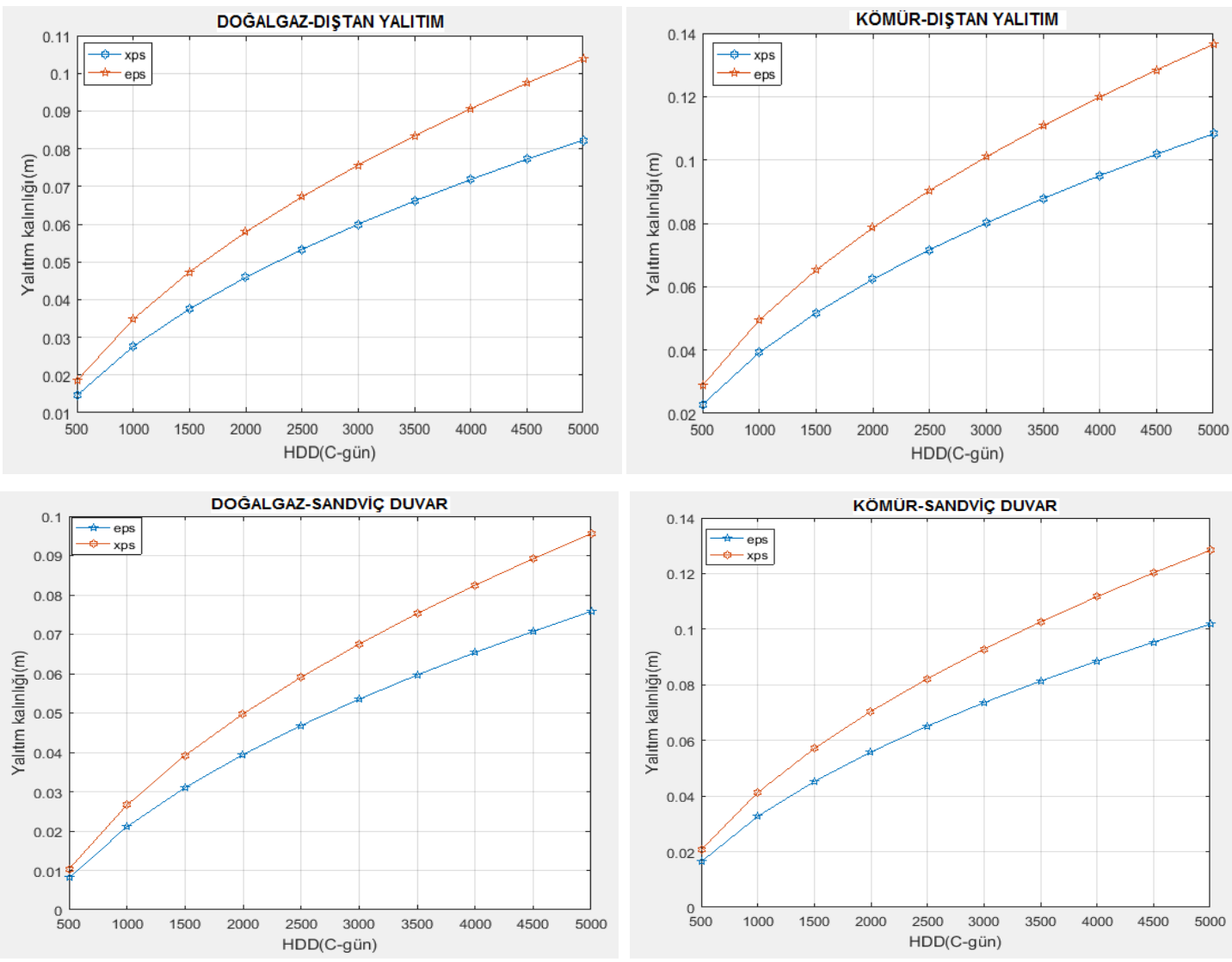

Şekil 5. Optimum yalıtım kalınlığının ısıtma derece gün sayısı ile değişimi
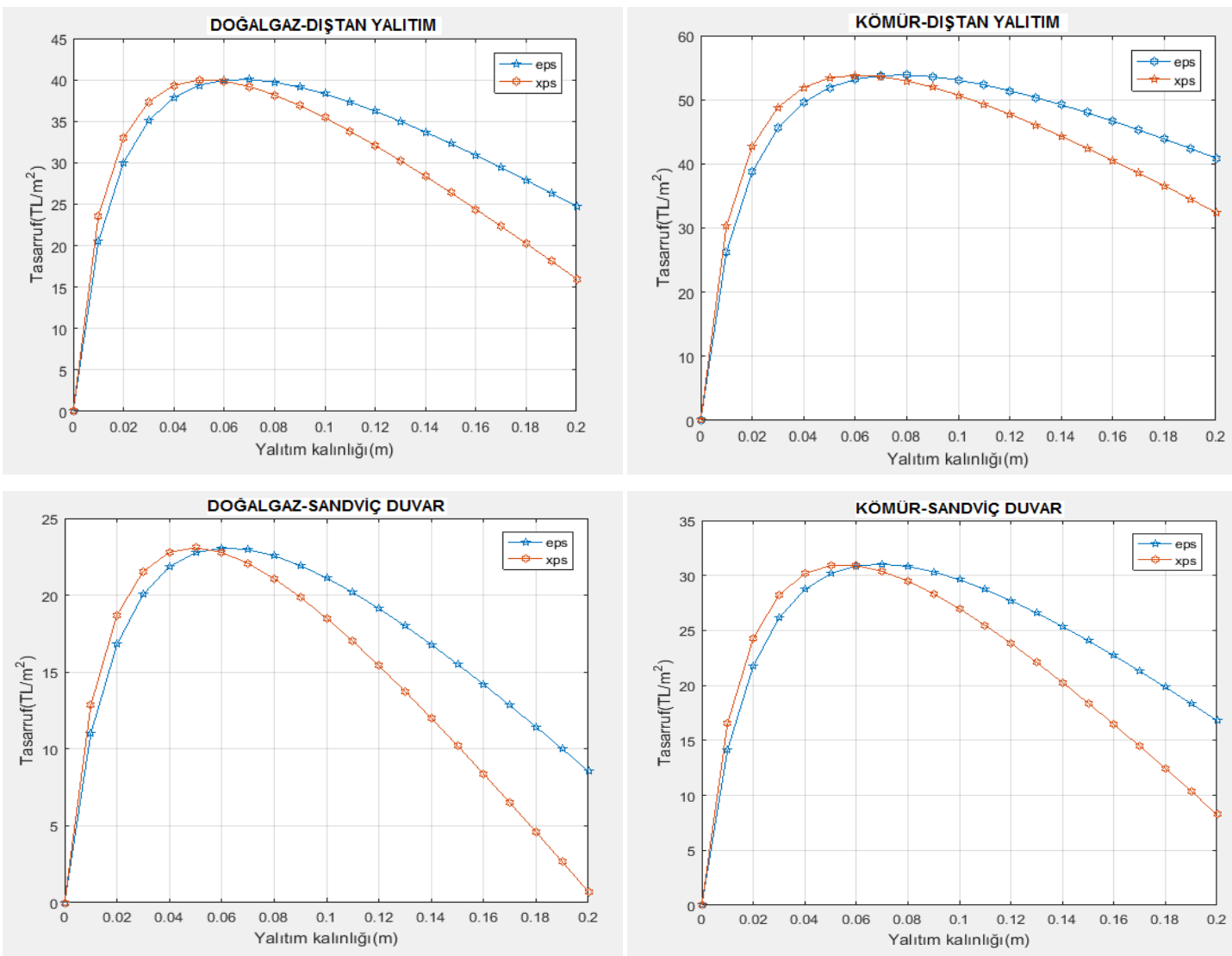

Şekil 6. Malatya ili için iki farklı yalıtım malzemesi için yalıtım kalınlığı ile tasarrufun değişimi 

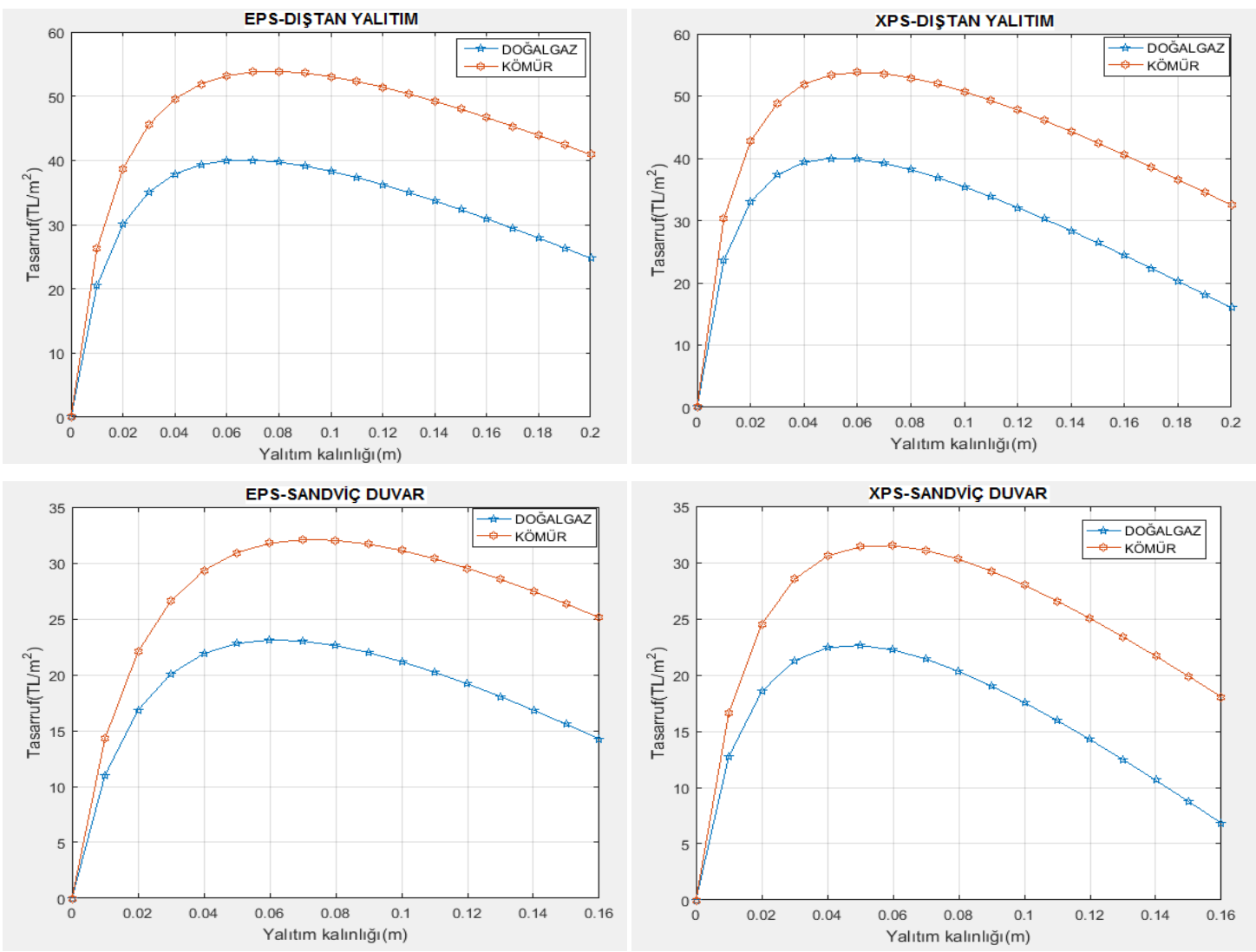

Şekil 6. Malatya ili için iki farklı yakıt türü için yalıtım kalınlığı ile tasarrufun değişimi

Şekil 5 ve Şekil 6'da iki farklı yalıtım malzemesi, iki farklı yakıt türü ile dıştan yalıtımlı ve sandviç duvar için yalıtım kalınlığının tasarrufa etkisi gösterilmektedir. Grafiklerden enerji tasarrufunun yalıtım kalınlığının artmasıyla birlikte arttığı görülmektedir. Yakıt olarak kömür kullanılması durumunda elde edilecek enerji tasarruf miktarı doğalgaz göre daha fazla olmaktadır. Bunun nedeni, kömürün düşük ısıl değer ve veriminin doğalgaza göre daha düşük olmasından dolayı birim alanı 1sıtmak için gerekli olan enerji maliyeti, kömür için doğalgaza göre daha fazla olmasıdır. Şekil 7'de geri ödeme süresinin ısıtma derece gün sayısı ile değişimi verilmektedir. Grafiklerden görüldüğü gibi, geri ödeme süresinin derece gün sayısı arttıkça geri ödeme süresinin azaldığı görülmektedir.
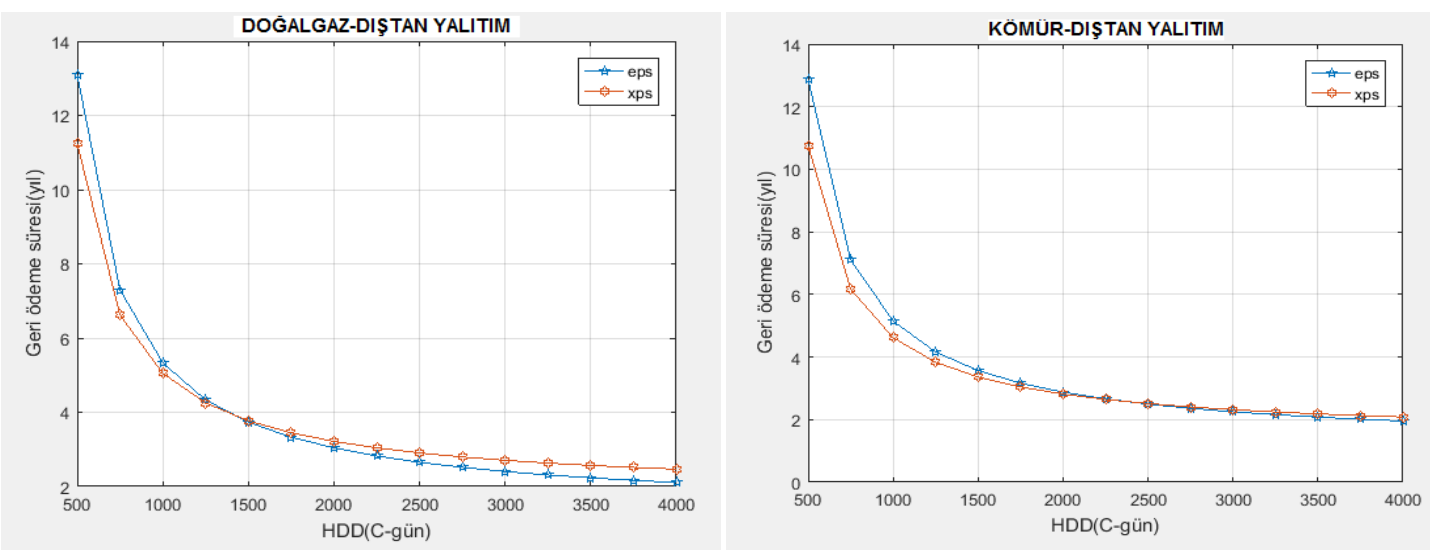

Şekil 7. Geri ödeme süresinin 1sıtma derece gün sayısı ile değişimi

Tablo 6. Sandviç ve dıştan yalıtımlı duvar için iki farklı yakıt türü ve yalıtım malzemesi için hesaplanan optimum yalıtım kalınlıkları, tasarruf ve geri ödeme süreleri

\begin{tabular}{|c|c|c|c|c|c|c|c|c|c|c|c|}
\hline & \multicolumn{5}{|c|}{ DOĞALGAZ } & \multicolumn{5}{|c|}{ KÖMÜR } \\
\hline & & $\begin{array}{c}\mathrm{X}_{\mathrm{optH}} \\
(\mathrm{m})\end{array}$ & $\begin{array}{c}\mathrm{X}_{\mathrm{optC}} \\
(\mathrm{m})\end{array}$ & $\begin{array}{c}\mathrm{X}_{\mathrm{optHC}} \\
(\mathrm{m})\end{array}$ & $\begin{array}{c}\mathrm{SA} \\
\left(\mathrm{TL} / \mathrm{m}^{2}\right) \\
\end{array}$ & $\begin{array}{c}\text { A } \\
\text { (y1l) }\end{array}$ & $\begin{array}{c}\mathrm{X}_{\mathrm{optH}} \\
(\mathrm{m}) \\
\end{array}$ & $\begin{array}{c}\mathrm{X}_{\mathrm{optC}} \\
(\mathrm{m}) \\
\end{array}$ & $\begin{array}{c}\mathrm{X}_{\mathrm{optHC}} \\
(\mathrm{m})\end{array}$ & $\begin{array}{c}\mathrm{SA} \\
\left(\mathrm{TL} / \mathrm{m}^{2}\right)\end{array}$ & $\begin{array}{c}\text { A } \\
(\mathrm{y} 1 \mathrm{l})\end{array}$ \\
\hline \multirow{2}{*}{ Sandviç } & EPS & 0.0617 & 0.0158 & 0.0719 & 24.83 & 4.1953 & 0.0690 & 0.0158 & 0.0788 & 31.03 & 3.8064 \\
\hline & XPS & 0.0489 & 0.0124 & 0.0549 & 24.79 & 4.2062 & 0.0547 & 0.0124 & 0.0624 & 30.98 & 3.8161 \\
\hline \multirow{2}{*}{$\begin{array}{c}\text { Disstan } \\
\text { yalitıml }\end{array}$} & EPS & 0.0665 & 0.02 & 0.0740 & 40.00 & 2.9403 & 0.0738 & 0.0 & 0.0836 & 53.81 & 2.5714 \\
\hline & XPS & 0.0559 & 0.0178 & 0.0587 & 53.87 & 2.9474 & 0.0585 & 0.0123 & 0.0645 & 60.45 & 2.5774 \\
\hline
\end{tabular}


Tablo 6'da Malatya ilinde sandviç ve dıştan yalıtımlı duvar için iki farklı yakıt türü ve yalıtım malzemesi için hesaplanan optimum yalıtım kalınlıkları, tasarruf ve geri ödeme süreleri verilmektedir. Dıştan yalıtımlı duvar da ısıtma için yakıt malzemesi olarak doğalgaz ve yalıtım malzemesi olarak EPS ve XPS seçilmesi durumunda; sırasıyla yalıtım kalınlıkları 0.0740 ve $0.0587 \mathrm{~m}$, yıllık tasarrufları 40.00 ve $53.87 \mathrm{TL} / \mathrm{m}^{2}$ olarak hesaplanmıştır. Sandviç duvar da ise yakıt olarak doğal gaz ve yalıtım malzemesinin EPS ve XPS olması durumunda, sırasıyla optimum yalıtım kalınlıkları $0.0836 \mathrm{ve} 0.0645 \mathrm{~m}$, yıllık tasarrufları $53.81 \mathrm{ve} 60.45 \mathrm{TL} / \mathrm{m}^{2}$ arasında bulunmuştur.

\section{Sonuç}

Yapılan bu çalışmada Türkiye'nin üçüncü derece gün bölgesinde bulunan Malatya ili için konutun sadece 1sıtılması, sadece soğutulması ve hem 1sıtma ve hem de soğutulması durumunda optimum yalıtım kalınlıkları, yıllık kazanç ve geri ödeme süreleri hesaplanmıştır. Bu amaçla MATLAB programı kullanılmıştır.

Dıştan yalıtımlı duvar da 1sıttma için yakıt malzemesi olarak doğalgaz ve yalıtım malzemesi olarak XPS ve EPS için, sırasıyla optimum yalıtım kalınlıkları 0.0587 ve $0.0740 \mathrm{~m}$, yıllık kazançları $53.87 \mathrm{ve} 40.00 \mathrm{TL} / \mathrm{m}^{2}$ iken, sandviç duvar da ise optimum yalıtım kalınlıkları $0.0645 \mathrm{ve} 0.0836 \mathrm{~m}$, yıllık tasarrufları $60.45 \mathrm{ve} 53.81 \mathrm{TL} / \mathrm{m}^{2}$ olarak hesaplanmıştır. Geri ödeme süresi derece gün sayısı arttıkça azaldığı ve dıştan yalıtımlı duvarda sandviç duvara göre yaklaşık \%30 daha kü̧̈ük olduğu sonuçlardan görülmektedir.

Konutların 1sıtma ve soğutma ihtiyacını azaltacak bina duvarlarında yapılan optimum kalınlıkta 1sı yalıtımı, hem enerji tasarrufu hem de doğaya salınan baca gazı emisyonlarını azaltması açısından önem kazanmıştır.

\section{Kaynakça}

Aktemur, C., Atikol, U. (2017). Optimum Insulation Thickness for the Exterior Walls of Buildings in Turkey Based on Different Materials. Energy Sources and Climate Regions, International Journal of Engineering Technologies-IJET: 3, 72-82.

Bolatturk, A. (2003). Binalarda Optimım Yalıtım Kalınlıklarının Hesabı ve Enerji Tasarrufundaki Rolü. 14. Ulusal Isı Bilimi ve Tekniği Kongresi, 41-47.

Canbolat, A. S., Bademlioglu, A. H., Kaynakli, O. (2018). Determination of proper insulation thickness for building walls regarding economic consideration. International Research Journal of Advanced Engineering and Science: 3, 173-176.

Çomaklı, K., Yüksel, B. (2003). Optimum Insulation Thickness of Extermal Walls for Energy Saving. Applied Thermal Engineering: 23,473-479.

Dombayci, Ö. A., Atalay, Ö., Acar, Ş. G., Ulu, E. Y., Ozturk, H.K. (2017). Thermoeconomic method for determination of optimum insulation thickness of external walls for the houses: Case study for Turkey. Sustainable Energy Technologies and Assessments: 22, 18.

Demir, H. (2018). Determination of Optimum Insulation Thickness Distribution for Refrigerators, Süleyman Demirel Üniversitesi Fen Bilimleri Enstitüsü Dergisi: 22 (1), 126-133.

Evin, D., Ucar A. (2019). Energy impact and eco-efficiency of the envelope insulation in residential buildings in Turkey. Applied Thermal Engineering: 154, 573-584.

Enerji dünyası dergisi, Teknik yayıncılık tanıtım AŞ, 2018.www.enerji-dunyasi.com

Faiz ve Enflasyon Oranları, 2018, www.tuik.gov.tr

Işık, E., \& Tuğan, V. (2017). Tunceli, Hakkâri ve Kars İllerinin Optimum Isı Yalıtım Kalınlığının Hesaplanması. International Journal of Pure and Applied Sciences, 3(2), 50-57.

Kaygusuz K., Kaygusuz A. (2004). Energy and sustainable development. Part II: Environmental inpacts of energy use. Energy Sources: 26, 1071-1082.

Kaynakl1, O. (2008). A Study on Residential Heating Energy Requirement and Optimum Insulation Thickness. Renewable Energy: 33, 1164-1172.

Kurekci, N.A. (2016). Determination of optimum insulation thickness for building walls by using heating and cooling degree-day values of all Turkey's provincial centers. Energy and Building.: 118, 197-213.

Nematchoua, M.K., Ricciardi, P., Reiter, S., Yvon, A. (2017). A comparative study on optimum insulation thickness of walls and energy savings in equatorial and tropical climate. International Journal of Sustainable Built Environment: 6, 170-182.

Ogulata, R.G. (2002). Sectoral energy consuption in Turkey. Renewable and Sustainable Energy Rewies: 6, 471-480.

Özel, M. (2018). Kars İlindeki Binalar İçin Isıtma Yükü ve Optimum Yalıtım Kalınlığının Belirlenmesi. Fırat Üniversitesi Mühendislik

Bilimleri Dergisi: 30 (1), 251-257. 


\section{Semboller}
A Geri ödeme süresi (yıl)
$\mathrm{C}_{\text {yakıt }}$ yakıtın birim fiyatı $\left(\mathrm{TL} / \mathrm{kg}, \mathrm{TL} / \mathrm{m}^{3}\right)$
$\mathrm{H}_{\mathrm{u}} \quad$ yakıtın 1 sıl değeri $(\mathrm{kj} / \mathrm{kg})$
CDD Soğutma derece-gün sayısı, $\left({ }^{\circ} \mathrm{C}\right.$-gün $)$
HDD Isıtma derece-gün sayısı, $\left({ }^{\circ} \mathrm{C}\right.$-gün)
$\mathrm{C}_{\mathrm{e}} \quad$ elektrik birim maliyeti (TL/kWh)
$\mathrm{C}_{\text {yal }} \quad$ Yalıtım malzemesinin birim fiyatı $\left(\mathrm{TL} / \mathrm{m}^{3}\right)$
COP soğutma performans katsayısı
x $\quad$ 1S1 yalıtım malzemesinin kalınlığ $(\mathrm{m})$
k 1sil iletim katsayısı (W/mK)
$\mathrm{R}_{\text {duvar }}$ yalıtımsız duvar katmanlarının 1 sıl direnci $\left(\mathrm{m}^{2} \mathrm{~K} / \mathrm{W}\right)$
$\mathrm{R}_{\mathrm{i}} \quad$ iç 1 sı transfer direnci $\left(\mathrm{m}^{2} \mathrm{~K} / \mathrm{W}\right)$
$\mathrm{R}_{\mathrm{o}} \quad$ dış $1 \mathrm{~S}$ ı transfer direnci $\left(\mathrm{m}^{2} \mathrm{~K} / \mathrm{W}\right)$
$\mathrm{R}_{\mathrm{yal}} \quad$ yalıtım malzemesinin 1 sıl direnci $\left(\mathrm{m}^{2} \mathrm{~K} / \mathrm{W}\right)$
$\mathrm{U}$ toplam $1 \mathrm{~s} 1$ transfer katsayıs $\left(\mathrm{W} / \mathrm{m}^{2} \mathrm{~K}\right)$
PWF şimdiki değer faktörü
SA enerji tasarrufu $\left(\mathrm{TL} / \mathrm{m}^{2}\right)$
g enflasyon oranı
i faiz oranı
r gerçek faiz oranı
$\mathrm{N} \quad$ ömür süresi (yıl)
$\eta \quad$ Yakma sisteminin verimi 